\title{
Direitos humanos, cidadania e liberdade de expressão
}

Maria Cristina Castilho Costa

Professora livre-docente do Departamento de Comunicações e Artes da Escola de Comunicações e Artes da Universidade de São Paulo. Editora da revista Comunicação \& Educação.

E-mail: criscast@usp.br

Resumo: A partir das discussões travadas em eventos realizados no ano de 2008, para rememorar os quarenta anos de promulgação do Al-5, no Brasil, e os sessenta anos de assinatura da Declaração Universal dos Direitos Humanos, no mundo todo, este texto comenta os diversos significados dos princípios de cidadania, liberdade e democracia, com base na análise dos conflitos históricos e dos anseios políticos de diferentes épocas. Da mesma forma, investiga a luta pela liberdade de expressão e a importância de discuti-la na atualidade.

Palavras-chave: Direitos Humanos, liberdade de expressão, história, comunicação.
Abstract: Using discussions which took place in events carried out in the year of 2008 - to remember 40th anniversary of the Al-5 enactment, in Brazil, and 60th anniversary of the Universal Declaration of Human Rights - this text analyses the several meanings of the principles of citizenship, freedom and democracy, considering the historical conflicts and the political aspirations of different eras. Likewise, it analyses the struggle for the freedom of expression and the importance of discussing it in current days.

Keywords: Human Rights, freedom of expression, History, communication.

Durante todo o ano de 2008, duas datas foram lembradas por diferentes instituições em diversos eventos: os sessenta anos da assinatura da Declaração Universal dos Direitos Humanos, comemorada no mundo todo, e, no Brasil, os quarenta anos do AI-5, Ato Institucional que oficializou a Ditadura Militar no país. São duas épocas que relembram fatos diferentes, mas indiretamente relacionados. Em 10 de dezembro de 1948, a recém-criada Comissão de Direitos Humanos da ONU (Organização das Nações Unidas) aprovava um documento que seria assinado por 48 países, reiterando os ideais democráticos e as liberdades políticas, numa rejeição explícita aos regimes políticos totalitários de tendências nazifascistas, derrotados na Segunda Guerra Mundial. Além de reafirmar os direitos civis de liberdade e igualdade perante a lei, o documento defendia também a justiça social, o direito à educação, saúde e moradia, além de exprimir os anseios pela paz e pela salvaguarda do meio ambiente. O Brasil foi um dos signatários desse documento.

Vinte anos depois, em 13 de dezembro de 1968, na condição de Presidente da República, o General Artur da Costa e Silva redigiu o AI-5, Ato Institucional 
1. O Grupo de Pesquisa Arquivo Miroel Silveira, que estuda a censura prévia ao teatro em São Paulo, promoveu o Seminário 1968 - Liberdade Repressão, com mesas de debates a respeito dessa época. n. 5, caçando as liberdades políticas no Brasil, fechando o Congresso e oficializando um regime ditatorial e de exceção. Tinha início uma das fases mais cruéis de nossa história, negando tudo o que, vinte anos antes, o país declarara defender: a liberdade, a democracia, a cidadania.

O ano de 2008 foi palco de comemorações, exposições, debates, seminários, congressos, publicações, depoimentos, promovidos por instituições políticas, escolas e universidades e pelos meios de comunicação. Procurava-se, de um lado, reafirmar os anseios democráticos de parte expressiva da população e, de outro, reavivar os temores em relação a uma tendência autoritária que tememos, sempre, ver eclodir entre os responsáveis pelos destinos da nação ${ }^{1}$. Assim, sucederam-se eventos - uns exaltando a resistência dos democratas que saíram fortalecidos dos confrontos mundiais do século XX, outros procurando alertar os brasileiros em relação a um passado tão temível e vergonhoso quanto recente.

Para nós, pesquisadores da comunicação e, em especial, defensores da liberdade de expressão, o debate que se estabeleceu em torno dessas rememorações foi de grande importância, pois permitiu reafirmar nossos anseios por cidadania, assim como analisar as transformações que ocorreram em torno desses ideais democráticos ao longo de séculos. Disso trata este artigo: da necessidade sempre presente de confirmar os princípios políticos civis e libertários, e de ter consciência daquilo que eles envolvem no mundo contemporâneo. Nosso objetivo é dividir com o leitor essas preocupações.

\section{CIDADANIA, UMA HERANÇA DA ANTIGUIDADE}

Vida política para nós, do Ocidente, implica ideias muito próximas e convergentes que incluem legitimidade do poder, participação política e direitos constituídos, garantindo igualdade e liberdade aos cidadãos. Esses conceitos deram sentido ao que entendemos por vida pública, um ideal perseguido por diferentes sociedades em diversas épocas e que teve origem em um momento remoto de nossa história - a sociedade helênica. Os helenos, ou gregos, como foram chamados pelos romanos, habitavam a Hélade, ou Península Balcânica, dedicando-se à agricultura e ao comércio com grande êxito. Essas atividades os colocaram em contato com outros povos, com os quais aprenderam a comerciar e a guerrear, resultando na emergência de grupos poderosos e enriquecidos, como os armadores e os militares.

A organização política dos helenos consistia em cidades-estado muito independentes e autônomas, que representavam as fronteiras da identidade política de cada grupo - um espartano era antes de tudo um espartano, assim como um ateniense era antes de mais nada ateniense. Esse forte sentimento de pertencimento estava alicerçado nos costumes familiares, na religião e, principalmente, em uma vida pública participativa e de forte sociabilidade. Inicialmente, o poder era exercido pela aristocracia agrária que transmitia por herança seus bens e autoridade. Mas grupos emergentes - comerciantes ricos e militares - ansiavam 
por partilhar decisões políticas e acabaram provocando mudanças que resultaram, em algumas cidades gregas, na criação da democracia - um regime que previa participação política e alternância do poder. Com ela, surgia também o estatuto da cidadania, privilégio de vida política para todo homem livre nascido em Atenas, o que significava apenas $20 \%$ de toda a população dessa cidade. Isso fazia da cidadania um princípio exclusivo e segregacionista que deixava de lado artesãos, escravos e todas as mulheres gregas. Embora formando, portanto, um contingente pequeno, esses cidadãos compunham júris e comissões e participavam de reuniões em que as opiniões eram manifestadas e as decisões tomadas por voto aberto e público. Essa vida política constituía a politeuma, que, segundo Toymbee, era o objetivo principal de todo heleno? ${ }^{2}$.

A cidadania era, portanto, um privilégio de poucos, mas opunha-se de forma inusitada à ideia do poder legitimado pela tradição, pela religião e pelo costume, transmitido por herança e exercido contra qualquer oposição ou dissidência. Não é de estranhar que o valor dado à vida pública tenha feito com que os gregos criassem a política, essa área do saber destinada a discutir a essência do poder.

Os romanos não foram insensíveis aos apelos da vida política e procuraram introduzir o conceito de cidadania no Império, mas suas dimensões e a natureza militar do poder instituído impediam uma vida realmente participativa - mesmo nos períodos de República, cidadãos mesmo eram apenas aqueles que viviam em Roma em torno do poder. De qualquer modo, permanecia o ideal de uma vida pública aberta à participação de grupos emergentes que, mesmo seletos, disputavam, dividiam, tomavam parte e legitimavam o poder. A democracia grega sucumbiria a guerras travadas contra povos invasores e rivais.

\section{9 - DECLARAÇÃO DOS DIREITOS DO HOMEM E DO CIDADÃO}

Na Modernidade, a ascensão da burguesia e o desenvolvimento do capitalismo fizeram com que novas classes emergentes ansiassem pelo poder monopolizado pela monarquia e pela corte. $\mathrm{E}$ assim como nas artes e em outros aspectos da cultura, a sociedade moderna buscou na Antiguidade clássica seus modelos. Dessa forma, ressuscitaram-se os ideais democráticos dos gregos que passaram a ser defendidos pela burguesia ascendente, desejosa de poder. O ápice dessa luta se deu na França, em 1789, com a Revolução Francesa, quando a Monarquia veio abaixo dando lugar à República, uma forma de governo burguesa, participativa e constitucional. Acontecimento marcante desse movimento foi a aprovação pela Assembleia Constituinte, em 26 de agosto do mesmo ano, da Declaração dos Direitos do Homem e do Cidadão.

Inspirado nos ideais iluministas, ou seja, em princípios de racionalidade, humanismo e liberalismo comercial e político, o documento pregava a liberdade individual, a igualdade de todos perante a lei, a resistência à opressão e a
2. TOYMBEE, A. J. A herança dos gregos. Rio de Janeiro: Zahar, 1984. p. 75. 
comunicação \& educação • Ano XIV • Número 2 - maio/ago 2009

propriedade privada, considerada fundamento da liberdade humana. Por mais que esses princípios nos pareçam, hoje, inconciliáveis, é preciso olhá-los à luz dessa época, quando representavam a instituição do Estado-Nação laico, cuja legitimidade repousava na Constituição e não mais no poder do sangue, da linhagem e da religião. Mesmo a propriedade privada não tinha o sentido que veio a ter depois, um princípio de desigualdade, mas, antes, de possibilidade de cidadãos sem origem nobre adquirirem bens fundiários e viver deles.

Porém, se por um lado a Declaração ressuscitava a visão laica e republicana do Estado proposta na Antiguidade, por outro, distanciava-se dos ideais helênicos, na medida em que a cidadania não se atinha aos limites da cidade, mas elegia a nação como território e entidade capaz de promover um legítimo sentimento de identidade. Além disso, os princípios da Declaração pretendiam-se válidos e aceitos por toda a humanidade, o que teria sido impensável entre os gregos, sempre mais centrados nas fronteiras das suas cidades de origem. $\mathrm{O}$ capitalismo se expandia e a sociedade humana adquiria novas dimensões - era preciso esquecer os parcos limites das cidades-estado gregas. Daí ser possível entender que:

[...] Os direitos humanos, em seu primeiro momento moderno, ou, como alguns denominam, em primeira geração, são a expressão das lutas da burguesia revolucionária, com base na filosofia humanista e na tradição doutrinária liberal, contra o despotismo dos antigos Estados absolutistas. Materializam-se, portanto, como direitos civis e políticos, ou direitos individuais atribuídos a uma pretensa condição natural do indivíduo ${ }^{3}$.

\section{SÉCULO XIX - O SOCIALISMO E O NOVO IDEAL DA JUSTIÇA SOCIAL}

Esses princípios liberais e democráticos se alastraram pelo mundo durante o século XIX, fazendo cada vez mais adeptos, tornando-se um verdadeiro movimento social de âmbito mundial, atingindo até mesmo as colônias europeias que lutavam por independência e autonomia. A rejeição à Monarquia se fazia unânime e muitas revoluções ocorreram em nome da República ou da Monarquia Constitucional. Mas à medida que avançava o capitalismo, as desigualdades sociais se tornavam cada vez mais evidentes, e filósofos, sociólogos e políticos procuravam entender as causas das injustiças sociais que resistiam à República e à luta pela ampliação dos direitos à cidadania. Karl Marx foi quem elaborou a mais consistente teoria crítica do capitalismo, mostrando que a grande questão humana não era a falta de liberdade individual, mas a desigualdade social resultante da propriedade privada dos meios de produção. $\mathrm{O}$ marxismo passou então a defender uma igualdade social de fato (e não apenas jurídica) através do socialismo, com um novo conceito de direitos civis e vida política que implicava a extinção da propriedade privada e do Estado-Nação.

Os movimentos socialistas que se organizavam em diferentes partes do Direitos Humanos. São Paulo: Brasiliense, 1993 p. 21 mundo, defendendo novos ideais políticos, iam transformando o conceito de direitos humanos. Em vez da liberdade e do individualismo, passava-se a alme- 
jar justiça social, igualdade econômica, dignidade humana, direito à moradia, segurança e saúde, além de trabalho digno e adequadamente remunerado.

Foram esses ideais que chegaram ao século XX e passaram a ser ameaçados com a ascensão dos regimes nazifascistas que, entre outros desafetos, combateram os partidos de esquerda e os movimentos socialistas. Quando esses governos foram derrotados em 1945, a Guerra Fria opôs essas duas propostas políticas conflitantes - o capitalismo liberal e o socialismo; o primeiro capitaneado pelos Estados Unidos e o segundo, pela União Soviética.

Em 1948, a Organização das Nações Unidas aprovou novo documento, a Declaração Universal dos Direitos Humanos, que espelha bem esse conflito entre diferentes maneiras de conceber o Estado e a sociedade. Em razão disso, países socialistas se abstiveram de votar o documento, mas, assim mesmo, ele trouxe princípios novos do que deveria ser o ideal político de todas as nações do mundo dali em diante - o pluralismo, o pacifismo, a globalização e a luta contra a xenofobia.

Boaventura de Sousa Santos, comparando as duas Declarações, a de 1789 e a de 1948, considera a primeira defensora dos direitos cívicos e políticos, e a segunda, dos direitos econômicos, sociais, culturais e de qualidade de vida. Entretanto, salienta que em 1789 procurava-se assegurar a soberania individual contra o Estado opressor, enquanto, em 1948, se defendia a soberania nacional ${ }^{4}$. O Estado passa a ser o responsável por assegurar aos cidadãos os seus direitos.

\section{DIREITOS E LIBERDADES INDIVISÍVEIS, INTERDEPENDENTES E INTER-RELACIONADOS}

A oposição entre uma proposta capitalista liberal e outra socialista com ideais políticos universais atravessou a segunda metade do século XX e esteve na raiz dos movimentos sociais, da luta política e das manifestações artísticas e culturais que caracterizaram a época contemporânea. A Ditadura Militar que ocorreu no Brasil em 1964, e que se tornou mais aguda em 1968, à época da promulgação do AI-5, também foi resultado desse embate entre duas propostas políticas, uma de direita e outra de esquerda. Tentou-se sabotar pela força a tentativa de implantar no país um modelo mais justo e coletivo de sociedade. As cicatrizes deixadas por esse momento foram amplamente revividas no ano que passou.

Além desse conflito entre propostas políticas diferentes, os movimentos sociais da segunda metade do século XX também levantaram outras bandeiras - as das minorias étnicas, religiosas e sociais que reivindicavam direitos civis, cidadania, inclusão social e o reconhecimento de necessidades específicas. O feminismo lutou por incluir as mulheres nas benesses da vida pública e por defender o direito de igualdade de gênero. À medida que esses movimentos iam ganhando visibilidade, Conferências Internacionais promovidas pela ONU procuraram incluir novos princípios e ideais de justiça social nessa agenda de luta política e reivindicatória.

4. SANTOS, Boaventura de Sousa. Uma concepção multicultural de Direitos Humanos. Lua Nova: revista de cultura e política, São Paulo: Centro de Estudos de Cultura Contemporânea (Cedec), n. 39, 1997. 
5. Disponivel em: <http:// www.pge.sp.gov.br/centrodeestudos/bibliotecavirtual/instrumentos/ viena.htm>

6. BOBBIO, Norberto. A era dos direitos. Rio de Janeiro: Campus, 1992. p. 67.

* Do francês "sem calção". A denominação era dada pelos aristocratas aos artesãos, trabalhadores e até pequenos proprietários participantes da Revolução Francesa. (N.E.)
Em 1993, a II Conferência Internacional de Direitos Humanos, realizada em Viena, referendou a abrangência internacional e a indivisibilidade dos diversos direitos do homem - econômicos, políticos e sociais. Diz a Declaração de Viena:

Todos os Direitos do homem são universais, indivisíveis, interdependentes e inter-relacionados. A comunidade internacional tem de considerar globalmente os Direitos do homem de forma justa e equitativa e com igual ênfase. Embora se devam ter sempre presentes o significado das especificidades nacionais e regionais e os antecedentes históricos, culturais e religiosos, compete aos Estados, independentemente dos seus sistemas político, econômico e cultural, promover e proteger todos os Direitos do homem e liberdades fundamentais ${ }^{5}$.

\section{IDEAIS POLÍTICOS E FATOS HISTÓRICOS}

As discussões ocorridas nos diversos eventos em memória desses fatos importantes foram unânimes em trazer à pauta dos debates algumas evidências. Em primeiro lugar, o reconhecimento de que os ideais de justiça, liberdade e cidadania pelos quais os homens veem lutando há séculos ainda é uma obra em construção. Eles continuam seduzindo as populações como algo cada vez mais desejável e difícil de ser alcançado. Autores como Norberto Bobbio falam do conflito existente entre a teoria e a prática dos Direitos Humanos, ante uma realidade em que a sua violação é cada vez mais inquestionável. Diz ele:

Num discurso geral sobre os direitos do homem, deve-se ter a preocupação inicial de manter a distinção entre teoria e prática, ou melhor, deve-se ter em mente, antes de mais nada, que teoria e prática percorrem duas estradas diversas e a velocidades muito desiguais. Quero dizer que, nestes últimos anos, falou-se e continua a se falar de direitos do homem, entre eruditos, filósofos, juristas, sociólogos e políticos, muito mais do que se conseguiu fazer até agora para que eles sejam reconhecidos e protegidos efetivamente, ou seja, para transformar aspirações (nobres, mas vagas), exigências (justas, mas débeis) em direitos propriamente ditos (isto é, no sentido em que os juristas falam de "direito") ${ }^{6}$.

Em segundo lugar, ficou claro que, aquilo que se considerava cidadania e liberdade na Antiguidade, pouco tinha a ver com o que mobilizava os revolucionários franceses de 1789. Consequentemente, a justiça social pela qual lutavam os signatários da Declaração Universal dos Direitos Humanos de 1948 jamais havia sido pensada pelos cidadãos atenienses do século IV a.C., ou mesmo pelos sans coulottes* franceses. Assim, por mais que os ideais de cidadania e vida pública participativa tenham alcançado universalidade, abrangência e unanimidade, não podemos deixar de reconhecer que eles só podem ser interpretados à luz de sua época e das propostas políticas conflitantes pelas quais lutamos.

Finalmente, se as discussões enfrentadas no ano que passou mostraram que os desafios atuais à defesa universal dos Direitos Humanos estão justamente em seu pluralismo e flexibilidade - valendo para diferentes sociedades, com diversas tradições, com grandes especificidades -, como reconhecer seus limites? Como estabelecer a convivência entre pluralismo e diversidade, de um lado, e conivência e tolerância, de outro? 


\section{LIBERDADE DE EXPRESSÃO E DIREITO À INFORMAÇÃO}

Para os pesquisadores particularmente interessados em um dos anseios fundamentais mencionados nos mais diferentes documentos que tratam dos Direitos Humanos - a liberdade de expressão -, esse debate é de fundamental importância. Também ela está sujeita aos contextos históricos, aos projetos políticos, às formas de produção e à tecnologia existente.

Como já haviam alertado autores como Julian Petley ${ }^{7}$, os estudiosos e críticos da censura não podem mais se ater àquilo que era defendido na Revolução Francesa, quando o que desejavam os congressistas signatários da Declaração dos Direitos do Homem e do Cidadão era a liberdade de criticar a monarquia e publicar livros sem o exame prévio de ministros censores. O campo da Comunicação foi um dos que mais se modificaram desde essa época, com a criação da imprensa e o desenvolvimento dos meios de comunicação. Quando, na Declaração Universal dos Direitos Humanos de 1948, se dizia: "Toda pessoa tem direito à liberdade de opinião e expressão; este direito inclui a liberdade de, sem interferência, ter opiniões e de procurar, receber e transmitir informações e ideias por quaisquer meios e independentemente de fronteiras", fazia-se menção explícita à internacionalização da informação e dos meios de comunicação.

Nessa época, defendiam-se o direito das pessoas às notícias, por mídia impressa, falada ou audiovisual, o direito dos veículos de chegar até elas e o direito ao uso de diferentes tecnologias. Ninguém pensaria mais simplesmente em um liberal desejando opor-se aos desmandos de um monarca, sem perigo de ser preso e condenado sem julgamento. A sociedade se tornara mais complexa e a expressão de ideias adquirira outro sentido.

Quando em 1993, na II Conferência Internacional de Direitos Humanos, se reiterou o direito à informação e à liberdade de expressão, as questões nas quais essa defesa implicava eram ainda mais complexas - a indústria cultural se estabelecera internacionalmente num mundo em que o fim das barreiras erguidas pela Guerra Fria tornara-o menor e mais homogêneo. A informatização da sociedade já era um fato e a aldeia global prevista por McLuhan, uma realidade. Isso significa que a liberdade de expressão de imediato representa uma conquista?

Certamente, não. É ainda dificultada ao cidadão que tece suas críticas ao poder instituído, mas o é também àquele jornalista que quer expressar a versão pessoal dos fatos os quais noticia; ao periódico que pretende veicular acontecimentos contrários aos interesses de seus anunciantes, ou aos interesses políticos dos poderosos e autoridades; aos artistas que dependem de subsídios governamentais ou do patrocínio de empresas privadas; aos escritores que não exaltam a elite política e econômica; às emissoras que teimam em não vender sensacionalismo.

Por essa complexidade envolvendo o campo da Comunicação, por mais que a liberdade de expressão faça parte dos ideais unânimes e universais deste

7. PETLEY, Julian. Censoring the Word (Censura da palavra). Oxford: Seagull Books, 2007. 
comunicação \& educação • Ano XIV • Número 2 • maio/ago 2009

século, sempre será importante analisar o contexto histórico no qual ela deva ser exercida, e, claro (!), por quem ou contra quem.

Outros autores vão mais longe e, ao desenvolverem seu trabalho investigativo sobre a liberdade de expressão, argumentam que, numa sociedade como a nossa, dominada pela mercantilização da informação, é preciso pensar também no direito à desinformação, ao silêncio e à inviolabilidade da vida privada. Essa é a discussão que estará em pauta nas próximas celebrações.

\section{REFERÊNCIAS BIBLIOGRÁFICAS}

BOBBIO, Norberto. A era dos direitos. Rio de Janeiro: Campus, 1992.

COSTA, Maria Cristina Castilho. Democracia. São Paulo: Global, 1985.

. Censura em cena. São Paulo: Imprensa Oficial/Edusp/Fapesp, 2006.

DORNELLES, João Ricardo W. O que são direitos humanos. São Paulo: Brasiliense, 1993.

GASPARI, Elio. A ditadura envergonhada. São Paulo: Companhia das Letras, 2002.

GREGORI, José. A herança bendita da Declaração Universal dos Direitos Humanos: globalização dos direitos, a universalidade dos Direitos Humanos e as peculiaridades nacionais. In: MARCílLIO, Maria Luiza. A Declaração Universal dos Direitos Humanos - Sessenta anos: sonhos e realidades. São Paulo: Edusp, 2008.

MARCÍlIO, Maria Luiza. A Declaração Universal dos Direitos Humanos Sessenta anos: sonhos e realidades. São Paulo: Edusp, 2008.

MONTESQUIEU, Charles. Considerações sobre as causas da grandeza e decadência dos romanos. In: LALLEMENT, Michel. História das ideias sociológicas: das origens a Max Weber. Petrópolis: Vozes, 2003.

PETLEY, Julian. Censoring the Word (Censura da palavra). Oxford/New York: Seagull Books, 2007.

SANTOS, Boaventura de Sousa. Uma concepção multicultural de Direitos Humanos. Lua Nova: revista de cultura e política, São Paulo: Centro de Estudos de Cultura Contemporânea (Cedec), 1997.

SOBOUL, Albert. A Revolução Francesa. Rio de Janeiro: Zahar, 1964.

SOUZA, José Inacio de Melo. O Estado contra os meios de comunicação (18891945). São Paulo: Annablume/Fapesp, 2003.

TOYMBEE, A. J. A herança dos gregos. Rio de Janeiro: Zahar, 1984. 